\section{PSYCHO-STATS PC: A statistical package for the IBM PC}

\author{
DAVID E. ANDERSON \\ Allegheny College, Meadville, Pennsylvania
}

Anderson's (1980) PSYCHO-STATS 80 package of computer programs was designed for the TRS-80 Model I microcomputer. PSYCHO-STATS PC represents both a translation and an extension of those programs for the IBM PC. The programs translated from the earlier version includes: (1) descriptive statistics; (2) Student's $t$ tests (independent and dependent samples); (3) one-way ANOVAs (simple, with repeated measures); (4) two-way ANOVAs (simple, with repeated measures on one factor and with repeated measures on two factors); (5) threeway ANOVAs (simple and with one or two repeated measures); (6) scatter diagram on a line printer; (7) nonparametric statistics (Kendall, KolmogorovSmirnov, Wilcoxon, Cochran, and Friedman); and (8) chisquare (single and double classification). In addition, programs to do multiple stepwise regression, frequency distributions (with histograms), and row $X$ column contingency tables have been added. The ANOVAs now provide the ability to do multiple comparisons and simple main effects analyses.

The author's mailing address is: Department of Psychology, Allegheny College, Meadville, PA 16335.
The entire program is menu driven and takes advantage of special features of the IBM PC, such as the numeric pad and function keys.

The major extension of the program has been in data entry and manipulation. After data have been entered, they can be displayed, deleted, added to, transformed, or stored on a diskette. Transformations were designed to parallel large statistical packages by providing COMPUTE and IF abilities. Extensive error detection and recovery routines are also provided.

A 50-page manual introduces each statistical routine and provides sample output.

Language and Computer. The programs are written in Microsoft BASIC for a $64 \mathrm{~K}$ or larger IBM PC under DOS 1.1 or 2.0. A printer and two disk drives are required.

Availability. Copies of the program and associated manual are available for $\$ 15$ (to cover diskette and mailing costs) from the author. Make checks payable to the Department of Psychology, Allegheny College.

\section{REFERENCE}

ANDERSON, D. (1980). PSYCHO-STATS PC: A basic statistical package for the TRS-80. Behavior Research Methods \& Instrumentation, 12,565 .

(Manuscript accepted for publication October 26, 1984.) 